\title{
Review Article \\ Present and Future in the Treatment of Diabetic Kidney Disease
}

\author{
Borja Quiroga, ${ }^{1}$ David Arroyo, ${ }^{2}$ and Gabriel de Arriba ${ }^{1,3}$ \\ ${ }^{1}$ Nephrology Unit, Hospital Universitario de Guadalajara, Spain \\ ${ }^{2}$ Nephrology Unit, Hospital Universitari Arnau de Vilanova, Lleida, Spain \\ ${ }^{3}$ Medicine and Medicine Specialities Department, Universidad de Alcalá (UAH), Madrid, Spain \\ Correspondence should be addressed to Borja Quiroga; borjaqg@gmail.com
}

Received 8 January 2015; Revised 26 March 2015; Accepted 27 March 2015

Academic Editor: Daisuke Koya

Copyright (C) 2015 Borja Quiroga et al. This is an open access article distributed under the Creative Commons Attribution License, which permits unrestricted use, distribution, and reproduction in any medium, provided the original work is properly cited.

\begin{abstract}
Diabetic kidney disease is the leading cause of end-stage renal disease. Albuminuria is recognized as the most important prognostic factor for chronic kidney disease progression. For this reason, blockade of renin-angiotensin system remains the main recommended strategy, with either angiotensin converting enzyme inhibitors or angiotensin II receptor blockers. However, other antiproteinuric treatments have begun to be studied, such as direct renin inhibitors or aldosterone blockers. Beyond antiproteinuric treatments, other drugs such as pentoxifylline or bardoxolone have yielded conflicting results. Finally, alternative pathogenic pathways are being explored, and emerging therapies including antifibrotic agents, endothelin receptor antagonists, or transcription factors show promising results. The aim of this review is to explain the advances in newer agents to treat diabetic kidney disease, along with the background of the renin-angiotensin system blockade.
\end{abstract}

\section{Introduction}

Diabetes mellitus (DM) and chronic kidney disease (CKD) have become two of the fastest growing pathologies worldwide $[1,2]$, while diabetic kidney disease (DKD) is still the leading cause of CKD and end-stage renal disease [2]. Population ageing and increase in prevalence of many interrelated comorbidities suggest that these numbers will worsen in the near future [3].

Despite emerging strategies and constant investigation, no current single treatment has been able to reverse or at least stop DKD progression. At best, some of the measures can partially slow the speed at which renal function is lost.

There are several possible reasons for this fact. First, most clinical trials have been addressed to evaluate the effect on albuminuria. Although albuminuria probably remains as the most influencing prognostic factor, up to one-fourth of normoalbuminuric diabetic patients will eventually develop CKD [4-6]. This has raised questions about the suitability of albuminuria as a surrogate marker in clinical trials, and renal function decline still remains as the most important target of nephroprotection $[7,8]$. On the other hand, a growing body of evidence is uncovering various mechanisms of renal injury in the context of DM, leading to the appearance of potential novel drugs.

In this review, we summarize the available evidence regarding classical treatments for diabetic nephropathy, as well as novel agents, paths, and targets under basic and clinical investigation.

\section{The Classical Nonspecific Measures}

2.1. Glycemic Control. DKD occurs in approximately $20 \%$ of diabetic patients, and it can appear despite a good glycemic control [9]. Nevertheless, many important studies have demonstrated that a tighter glycemic control can delay the onset of DKD and slow its progression, beyond its wellknown cardioprotective effect. This effect has been proved valid in both type 1 and type $2 \mathrm{DKD}$ and in the short and long terms [10-16]. However, the risk of severe hypoglycemic adverse events prompted a change in international guidelines, which currently recommend individualization in treatment intensity according to patients' characteristics $[17,18]$. Glycemic control can be achieved through diverse pharmacological treatments. Some of them, such as incretin degradation inhibitors or glucagon-like peptide analogues, 
may have specific nephroprotective effects independent of their glycemic impact, but these results require confirmation $[19,20]$.

2.2. Blood Pressure Control. Given the pathogenetic importance of intraglomerular hypertension in the initiation of $\mathrm{DKD}$, earlier guidelines recommended a stricter blood pressure control in diabetic patients [21]. The latest 2012 KDIGO guidelines maintain a tighter blood pressure recommendation for proteinuric patients, regardless of etiology [22]. However, more recent data from several studies in the field of hypertension have evidenced the risks of hypotensive episodes and their vascular consequences [23, 24]. Hence, similarly to the evolution of recommendations in glycemic control, a more individual approach to blood pressure targets is advised [17].

2.3. Weight Loss. Overweight and obesity are frequent comorbidities to diabetes and play an important role in the pathogenesis of CKD [25]. This may be due both to a further increase in hyperfiltration and to specific hormonal dysregulations related to adipokines [26]. Weight loss in obese diabetic patients has been shown to markedly reduce albuminuria [27]. A decrease in serum creatinine has also been demonstrated in very hypocaloric diets, but this effect could be secondary to muscular mass loss [28]. There is also growing evidence about the beneficial effects of bariatric surgery in morbid obese patients over diabetes, renal function, and albuminuria $[29,30]$, but no trial has been yet specifically designed to analyze this effect on DKD.

2.4. Protein Restriction. Dietary advice in DKD patients is a complex issue: it compels carbohydrate consumption regulation, but the frequent concurrence of comorbidities also requires a low-salt diet for hypertension, fat-free for dyslipidemia, and hypocaloric intake for obesity. There is evidence of the benefits of moderate protein restriction up to $0.8 \mathrm{~g} / \mathrm{kg} /$ day [31-33], and this indication is included in international guidelines at least for patients with reduced glomerular filtration rates (GFR) [21].

2.5. Smoking Cessation. Cigarette smoking has been linked to the appearance and progression of DKD, probably due to oxidative stress stimulation, and the cessation of this habit has also been associated with slower progression of the nephropathy [34-36]. If not for this reason, strong smoking cessation support should be offered to all diabetic and/or CKD patients as a means to reduce their increased vascular risk.

\section{Past and Present: Renin-Angiotensin- Aldosterone System Blockade}

3.1. ACEI and $A R B$. One of the most important risk factors for kidney disease progression in diabetic patients is the onset and persistence of proteinuria [37]. The use of angiotensin converting enzyme inhibitors (ACEI) or angiotensin II receptor blockers (ARB) to reduce proteinuria is currently the firststep strategy $[17,18,38]$. This benefit is valid for both type 1 and type 2 diabetic patients, even with low-grade proteinuria and normal GFR [39, 40].

Many clinical trials have been performed in this respect. A different approach that has attracted much attention has aimed to demonstrate the usefulness of combining two or even three of these drugs. The efficacy for lowering proteinuria with the combination of renin-angiotensin-aldosterone system blockers is at least the same as using one of them at maximum dosage. However, published studies have not succeeded in demonstrating these positive outcomes with the same adverse effects (renal function decline or hyperkalemia in the combination arms of several trials forced to stop some of them). While using ARB or ACEI to lower proteinuria in $\mathrm{DKD}$ and in proteinuric CKD is considered mandatory (evidence grade 1A), the lack of positive studies has encouraged a change in current recommendations against the use of dual blockade [41-43]. In spite of this fact, dual blockade is spreading more than ever, as shown in a recent retrospective study that included a great number of diabetic patients [44].

In a more detailed analysis of these trials (Table 1), ACEI and ARB combined treatment efficiently decreases proteinuria, and adverse events are usually limited to hyperkalemia and renal impairment [44]. For these reasons, we recommend that, in adequately selected cases with very high urinary protein excretion, dual blockade can probably be tried as long as a close monitoring can be ensured [50].

The unsolved issue is probably to find the optimal drug doses. The ROAD study showed that uptitration to the highest tolerated dose can be an interesting strategy to avoid adverse effects while achieving the maximum reduction in proteinuria [51]. In this sense, the use of a combination with equipotent doses of ACEI and ARB is not supported, due to a lack of benefits in terms of proteinuria as shown in the PRONEDI trial [42].

The controversy about an early treatment of nonproteinuric diabetic patients still remains. In the ROADMAP trial, proteinuria had a delayed onset in those patients treated with olmesartan, although at the expense of higher rates of cardiovascular events [23]. This benefit in primary prevention of DKD had been previously demonstrated with trandolapril in the BENEDICT trial [52]. A review and meta-analysis of the Cochrane Database concluded that ACEI could reduce the risk for new onset of albuminuria, but this effect cannot be proved with the use of ARB [53].

3.2. Aliskiren. Another option that has been proposed is the use of a selective inhibitor of human renin in combination with an ACEI, an ARB, or an aldosterone blocker. Aliskiren is a direct renin inhibitor that has been tested as an antiproteinuric agent in DKD. The AVOID trial generated important evidence about the efficacy of this drug with a nonsignificant rise of adverse effects (the aliskiren group developed more hyperkalemia, but the difference did not achieve statistical significance). However, the security profile of this treatment was questioned after the premature stop of the ALTITUDE trial due to a higher rate of adverse effects in an intermediate analysis $[45,46]$. For this reason, the use of aliskiren in combination with ACEI/ARB is not supported for lowering proteinuria in kidney disease. 
TABLE 1: Most relevant clinical trials assessing dual blockade of renin-angiotensin-aldosterone system in diabetic nephropathy.

\begin{tabular}{|c|c|c|}
\hline Study & Patients and treatment arms & Commentary \\
\hline \multicolumn{3}{|c|}{ Dual blockade using ACEI and ARB } \\
\hline \multirow{2}{*}{ VA NEPHRON-D [41] } & 724 (losartan $100 \mathrm{mg} /$ day) & Stopped due to adverse effects. \\
\hline & 724 (losartan 100 mg/day + lisinopril 10-40 mg/day) & $\begin{array}{l}\text { Primary endpoint included change in eGFR, death, } \\
\text { or end-stage renal disease. }\end{array}$ \\
\hline ONTARGET [43] & $\begin{array}{l}8576 \text { (ramipril } 10 \mathrm{mg} / \text { day) } \\
8542 \text { (telmisartan } 80 \mathrm{mg} / \text { day) } \\
8502 \text { (both) }\end{array}$ & $\begin{array}{l}\text { Telmisartan equivalent to ramipril. } \\
\text { No benefit of combination in proteinuria. } \\
\text { Worse eGFR in combination group. }\end{array}$ \\
\hline PRONEDI [42] & $\begin{array}{l}35 \text { (lisinopril } 40 \mathrm{mg} / \text { day) } \\
28 \text { (irbesartan } 600 \mathrm{mg} / \text { day) } \\
70 \text { (lisinopril } 20 \mathrm{mg} / \text { day + irbesartan } 300 \mathrm{mg} / \text { day) }\end{array}$ & $\begin{array}{l}\text { No benefit of combination in proteinuria or renal } \\
\text { function. }\end{array}$ \\
\hline \multicolumn{3}{|c|}{ Dual blockade using aliskiren } \\
\hline ALTITUDE [45] & 8561 (ACE/ARB + aliskiren 300 mg/day) & $\begin{array}{l}\text { Stopped due to adverse effects. } \\
\text { Greater reduction in proteinuria. } \\
\text { Renal function was included in the primary } \\
\text { endpoint. }\end{array}$ \\
\hline \multirow{2}{*}{ AVOID [46] } & 298 (losartan 100 mg/day) & $\begin{array}{l}\text { Greater reduction in proteinuria without differences } \\
\text { in the decline of eGFR. }\end{array}$ \\
\hline & 301 (losartan 100 mg/day + aliskiren $150-300$ mg/day) & No increased risk of adverse events. \\
\hline \multicolumn{3}{|c|}{ Dual blockade using aldosterone blockers } \\
\hline Sato et al. [47] & $\begin{array}{l}55 \text { (spironolactone } 25 \mathrm{mg} / \text { day to those patients with } \\
\text { aldosterone escape after ACEI) }\end{array}$ & $\begin{array}{l}\text { Early stage of CKD }\left(e G F R>60 \mathrm{~mL} / \mathrm{min} / 1.73 \mathrm{~m}^{2}\right) \text {. } \\
\text { Greater reduction in proteinuria. } \\
\text { No increased risk of adverse events. }\end{array}$ \\
\hline \multirow{2}{*}{ Esteghamati et al. [48] } & 62 (enalapril 30-40 mg/day + losartan 50-100 mg/day) & Greater reduction in proteinuria. \\
\hline & 74 (spironolactone $25 \mathrm{mg} /$ day + losartan $50 \mathrm{mg} /$ day) & Greater loss of eGFR. \\
\hline Epstein et al. [49] & $\begin{array}{l}91 \text { (enalapril } 20 \mathrm{mg} / \text { day) } \\
91 \text { (enalapril } 20 \mathrm{mg} / \text { day + eplerenone } 50 \mathrm{mg} \text { ) } \\
86 \text { (enalapril } 20 \mathrm{mg} / \text { day + eplerenone } 100 \mathrm{mg} / \text { day) }\end{array}$ & $\begin{array}{l}\text { Greater reduction in proteinuria in combination. } \\
\text { No differences in eGFR reduction. } \\
\text { No increased risk of hyperkalemia in combination. }\end{array}$ \\
\hline
\end{tabular}

ACEI: angiotensin converting enzyme inhibitor; ARB: angiotensin II receptor blockers; mg: milligram; eGFR: estimated glomerular filtration rate; CKD: chronic kidney disease.

3.3. Spironolactone and Eplerenone. The benefits of the addition of an aldosterone blocker to the standard therapy in DKD have been noted in some clinical trials $[54,55]$. Beyond the mere addition of spironolactone or eplerenone, these drugs have demonstrated slight renoprotective superiority in small studies compared to ACEI or ARB therapies [56]. For example, a recent study conducted by Esteghamati et al. including 136 patients that were using dual blockade with ACEI and ARB demonstrated that the substitution of the first one by spironolactone provides additional benefits in terms of proteinuria reduction with the same profile of adverse effects after 18 months of follow-up [48]. However, a reduction in GFR was noted in the spironolactone group, independent of blood pressure control. In CKD, this drop in renal function has been reported by other authors, but it appears reversible after the first treatment weeks $[57,58]$. Although this beneficial effect is not well understood, it is hypothesized that these drugs avoid the aldosterone escape that happens in up to $40 \%$ of patients treated with an ACEI (Table 1) [47]. In an interesting study conducted by Sato et al., 55 patients received maximum doses of an ACEI. Of these, 18 patients showed aldosterone escape, so spironolactone was started. After 24 weeks, proteinuria was significantly reduced, showing no adverse effects [57].
Regarding the use of eplerenone, only one clinical trial has assessed the antiproteinuric value of this aldosterone blocker [49]. Epstein et al. demonstrated in a randomized double-blind study that eplerenone decreased albuminuria in diabetic patients at 4-, 8-, and 12-week follow-up. No differences in adverse effects were seen.

In spite of these good results, and given that these trials were only performed in early CKD stages, we must still be cautious until larger studies with long-term follow-up are published. Potential adverse events must still be closely monitored, especially hypotension, hyperkalemia, and renal failure [59].

\section{Present: Beyond Renin-Angiotensin-Aldosterone System}

Blocking renin-angiotensin system is not always enough to avoid proteinuria, so other approaches have been proposed. The formerly unexplored fields of inflammation and oxidative stress now become more important as targets for new treatments. Unfortunately, most of the studies performed yield incomplete conclusions or results that have not been confirmed in other studies [60]. 
4.1. Bardoxolone Methyl. Bardoxolone methyl is an antioxidant agent that activates Keap1-Nfr2 [nuclear 1 factor (erythroid-derived 2)-related factor 2] pathway and regulates inflammation in the kidney. However, the inhibition of this pathway focusing on slowing CKD progression in diabetic animals has produced controversial conclusions [61, 62]. Nrf2-deficient mice do not develop hyperfiltration in response to hyperglycaemia but experience a faster decline in renal function. In addition, some studies report different degrees of proteinuria in diabetic Nrf2 knock-out mice.

In humans, two relevant clinical trials have been published with bardoxolone methyl in DKD. The BEAM trial included 227 CKD patients (GFR between 20 and $45 \mathrm{~mL} / \mathrm{min} / 1.73 \mathrm{~m}^{2}$ ) that were randomized to placebo or various doses of bardoxolone for 52 weeks [63]. GFR increased significantly in all the bardoxolone arms, with a peak at 12 weeks that then remained stable. One of the most important results of the study regarding renal function was that albumin-to-creatinine ratio (ACR) was raised inversely to GFR in the treatment group. However, four weeks after treatment discontinuation, ACR returned to baseline levels. Besides, adverse effects were more frequent in the bardoxolone groups, especially muscle spasms (that reached $61 \%$ in the $75 \mathrm{mg}$ group).

The BEACON trial was designed to confirm the findings of the BEAM trial, but it was stopped prematurely due to unacceptable high rates of cardiovascular events in the bardoxolone methyl arm [64]. In this study, 2185 type 2 diabetic CKD patients were randomized to receive placebo or $20 \mathrm{mg}$ /day of bardoxolone methyl. A composite cardiovascular endpoint (nonfatal myocardial infarction, stroke, heart failure, or cardiovascular death) was achieved after a median exposure time to the drug of 7 months, so the trial was terminated due to safety concerns.

Recently, a derivative of bardoxolone methyl, an Nrf2 agonist called $d h 404$, has shown beneficial effects in mice via decreasing inflammation and oxidative stress, but only at low doses. This study reopens the interests on the Nrf2 pathway in renoprotection in DKD [65].

4.2. Vitamin D Receptor Activation: Paricalcitol. Vitamin D is a well-known modulator of many different processes, and its deficiency can drive abnormalities in immune system, inflammation, or even cardiovascular events [49]. In addition, lower 25-OH-vitamin D levels have been independently linked to DKD progression in a subanalysis of the PRONEDI study [66]. The pleiotropic effects of vitamin D receptor activation have aroused a growing interest in some drugs, such as paricalcitol [67].

The presence of vitamin $\mathrm{D}$ receptors in podocytes has promoted several clinical studies, with the hypothesis of an effect of podocyte modulation on proteinuria. Agarwal et al. designed a small trial of 113 diabetic patients randomized to placebo or paricalcitol, demonstrating proteinuria reduction with paricalcitol qualitatively assessed by dipstick [68]. This effect was later confirmed in the VITAL study, published by de Zeeuw et al. [69]. In this study, 281 patients were randomized to receive placebo or 1 or $2 \mu \mathrm{g}$ /day of paricalcitol for
24 weeks. Only $40 \%$ of the patients were receiving maximum doses of ARB or ACEI, and the median of urinary ACR was $612.3 \mathrm{mg} / \mathrm{g}$ [70]. Proteinuria was not reduced in patients with paricalcitol at any dose when compared to placebo, but albuminuria was significantly reduced in patients with higher sodium intakes. It should be noted that only $58 \%$ of the patients assigned to $2 \mu \mathrm{g} /$ day of paricalcitol received the full dose during the whole study, due to adverse effects.

A recent paper published by Eren et al. demonstrates that the combination of paricalcitol with other drugs such as aliskiren can reduce DKD progression in rats beyond the simple reduction of proteinuria, when the renin-angiotensin system is adequately blocked [71]. In this study, the main finding was that paricalcitol in association with aliskiren reduced interstitial fibrosis.

A recent systematic review that included clinical trials about the effect of active vitamin D (both paricalcitol and calcitriol) on the control of proteinuria in CKD concludes that these drugs provide a significant reduction in proteinuria in addition to rennin-angiotensin system blockade. However, except the VITAL trial, the rest of the included studies were small in sample size, and the underlying conditions differed between them (like the etiology of the proteinuric state) [72].

4.3. Pentoxifylline. Both insulin resistance and diabetes are linked to inflammation. This fact has generated a growing interest in anti-inflammatory therapies to slow diabetes and DKD progression [73]. Indeed, diabetes is now considered an inflammatory disease.

Pentoxifylline is a methylxanthine derivative and a nonspecific phosphodiesterase inhibitor of tumor necrosis factor (TNF- $\alpha$ ) that has demonstrated an antiproteinuric effect in DKD $[71,74]$. However, the heterogeneity and short followup of published studies have turned pentoxifylline away from the usual therapeutic arsenal against diabetes.

A well-designed long-term trial by Navarro-González et al. has been recently published. One hundred and sixty-nine diabetic patients with 3-4 stage CKD were randomized to placebo or pentoxifylline $600 \mathrm{mg}$ daily one month, followed by $600 \mathrm{mg}$ twice daily for 23 more months. All of them were receiving renin-angiotensin system blockers and the median of urinary albumin excretion was 1.1 grams per day. The study concludes that pentoxifylline slows renal disease progression (GFR slope) after the first year of treatment and maintained a statistically significant difference with placebo after 24 months [75]. Our group had previously published a small trial including $91 \mathrm{CKD}$ patients, showing that pentoxifylline stabilizes renal function at 12 months, while patients in the placebo arm experienced a decline in renal function (estimated by MDRD) [76]. In the PREDIAN trial, urinary albumin excretion was reduced (mean of reduction difference of $20.6 \%$ between groups) in the pentoxifylline group at 6 , 12,18 , and 24 months. Surrogate markers of inflammation also decreased at the end of the study in those patients receiving pentoxifylline [73]. These results therefore place pentoxifylline as one of the first-line drugs to be used in addition to renin-angiotensin system to avoid or at least decrease residual proteinuria in diabetic kidney disease. 
TABLE 2: Summary of main pathogenic pathways and agents under evaluation for diabetic nephropathy.

\begin{tabular}{|c|c|c|}
\hline Mechanism & Agent & Situation \\
\hline \multicolumn{3}{|c|}{ Endothelin-receptor antagonism } \\
\hline & Avosentan & Stopped due to adverse events \\
\hline & Atrasentan & Ongoing RCT \\
\hline \multicolumn{3}{|c|}{ Antioxidant agents } \\
\hline \multirow{2}{*}{ Direct renal effect } & N-Acetylcysteine & Inconclusive results \\
\hline & Probucol & Apparent positive results \\
\hline \multirow{2}{*}{ Xanthine oxidase inhibition } & Allopurinol & Ongoing RCT \\
\hline & Febuxostat & Ongoing RCT \\
\hline \multicolumn{3}{|c|}{ Transcription factor modulation } \\
\hline \multirow{3}{*}{ Protein kinase modulation } & Ruboxistaurin & Stopped due to adverse events \\
\hline & Imatinib & Animal models/other indications \\
\hline & Fasudil & Animal models \\
\hline JAK-STAT pathway inhibition & Baricitinib & Ongoing RCT \\
\hline \multirow{3}{*}{ Neurohormonal modification } & D3-RA & Animal models \\
\hline & Sarpogrelate & Ongoing RCT \\
\hline & ACTH & Ongoing RCT \\
\hline \multirow{2}{*}{ Endogenous agents } & Apelin & Animal models \\
\hline & Activated protein $\mathrm{C}$ & Animal models \\
\hline \multicolumn{3}{|c|}{ Antifibrotic agents } \\
\hline Anti-TNF $\alpha$ & Infliximab & Animal models/other indications \\
\hline \multirow{2}{*}{ Anti-TGF $\beta$} & Pirfenidone & Stopped due to adverse events \\
\hline & Fresolimumab & Ongoing RCT \\
\hline Anti-CTGF & FG3019 & Animal models \\
\hline Chemokine inhibition & CCX $140-B$ and others & Ongoing RCT \\
\hline \multirow[b]{2}{*}{ MMP inhibition } & Tetracyclines & Ongoing RCT \\
\hline & XL081, XL874 & Limited efficacy \\
\hline miRNA modulation & LNA-anti-miR-192 & Animal models \\
\hline \multicolumn{3}{|c|}{ Other agents } \\
\hline \multirow{2}{*}{ RAGE inhibition } & Pimagedine & Stopped due to adverse events \\
\hline & Pyridoxamine & Ineffective \\
\hline Oral adsorbents & Kremezin & Moderate efficacy \\
\hline Urotensin-II inhibition & Palosuran & Ineffective \\
\hline Glycosaminoglycans & Sulodexide & Ineffective \\
\hline
\end{tabular}

RCT: randomized controlled trial; JAK-STAT: Janus kinase-signal transducer and activator of transcription; ACTH: adrenocorticotropic hormone; TNF- $\alpha$ : tumor necrosis factor $\alpha$; TGF- $\beta$, transforming growth factor $\beta$; CTG: connective tissue growth factor; miRNA: microRNA; RAGE: receptor of advance glycation end-products.

4.4. Other Approaches. Some studies have tried to show beneficial effects of other drugs such as statins, aspirin, or rapamycin [77-80]. These anecdotal results should be cautiously managed, until studies designed with hard endpoints reveal further evidence.

\section{Present and Future: Novel Drugs for Novel Approaches}

An increasing knowledge of pathogenic mechanisms in DKD beyond proteinuria has enhanced studies of new molecules that could interfere in CKD progression (Table 2).

5.1. Endothelin Receptor Antagonists. Endothelins are small vasoactive peptides that influence hypertension and CKD through various mechanisms, including endothelial dysfunction, vasoconstriction, cell damage, and albuminuria $[81,82]$. Their action is mediated through two families of receptors: endothelin-1 receptor (ETA) has been implied in the deleterious effects of endothelins, while endothelin$B$ receptors (ETB) act in the proximal tubule enhancing sodium excretion. All endothelin inhibitors have demonstrated positive effects on the kidney, by reducing proteinuria and renal function loss. However, the effect of inhibiting ETB results in inappropriate sodium retention, with more episodes of peripheral edema, congestive heart failure, and cardiovascular events. Unfortunately, this mishap happens with all known endothelin inhibitors, since they all have an effect on both ETA and ETB. Although first described with the earlier bosentan, molecules with higher selectivity on ETA over ETB like sitaxsentan and avosentan also showed these adverse events, which led to early termination of several trials [83-85]. Currently, the SONAR study is evaluating the effect of atrasentan on renal endpoints in type- 2 diabetic patients [86], but it excludes patients with a history of peripheral edema or heart insufficiency and those with higher levels of type-B natriuretic peptide, so a limitation in its future indications is expected. 
5.2. Antioxidant Therapies. Oxidative stress is part of the hyperglycemic-generated renal dysfunction. Several vitamin analogs and other molecules that inhibit redox reactions (such as taurine, luteolin, D-saccharic 1,4-lactone, silybin, or hemin) have proved to diminish kidney damage in animal models by normalizing superoxide dismutase, inducing hemoxygenase, or inhibiting NADPH oxidase [87-91]. NAcetylcysteine, which has been tested in many clinical trials for the prevention of contrast-induced nephropathy with controversial results [92], has not yet been proved effective in DKD, although studies are too small to be conclusive $[93,94]$. Probucol is another antioxidant drug that has shown nephroprotective capacity besides its hypolipidemic use [95].

Results regarding inhibition of xanthine oxidase are more promising. Allopurinol has already shown efficacy in preventing vascular events and slowing kidney function loss in several clinical trials $[96,97]$, some of which included diabetic patients. The ongoing clinical trials PEARL and FEATHER are currently investigating the specific usefulness of allopurinol, and its novel analogue febuxostat, in type 2 DKD $[98,99]$.

5.3. Transcription Factor Modulation. There are many attempts to interfere with the inflammatory pathways of DKD, aiming to interrupt the fibrotic pathogenesis. Some of these attempts are addressed at the earlier phases of the process, by inhibiting several transcription factors.

Protein-kinase activity is directly related to fibrosis [100], and several molecules have been studied to inhibit them. Ruboxistaurin, a protein-kinase $\mathrm{C}$ inhibitor, showed promising initial results in the fields of retinopathy and peripheral neuropathy $[101,102]$. Data on DKD are very scarce with either negative effects [103] or a discreet benefit on protein excretion and GFR loss in the long term [104, 105]. However, these results have not been confirmed in larger populations or in patients with a decreased GFR. Other protein-kinase inhibitors are under current evaluation after associating renal benefits in animal models: tyrosine-kinase inhibitors imatinib, nilotinib, genistein, and PP2 [106-109], Rhokinase inhibitors fasudil and Y27632 [110-112], p38-MAPK inhibitor FR167653 [113, 114], phosphoinositide 3-kinase (PI3K) inhibitors wortmannin, IC87114, and AS101 [115-117], or activin-like kinase 3 agonists (Alk-3) THR-123 [118].

The Janus kinase-signal transducer and activator of transcription (JAK-STAT) system has also been related to kidney damage [119]. Baricitinib is a JAK inhibitor currently under evaluation or rheumatoid arthritis that is also being studied for DKD [120].

Transcription processes can also be indirectly regulated through neurohormonal paths. The most studied pathway in this area is vitamin $\mathrm{D}$ receptor activation, but other ways are under evaluation. On the one hand, dopamine has been involved in blood flow regulation and hyperfiltration in earlier diabetic kidney disease. Experimental antagonism of D3 receptor with D3-RA showed beneficial effects on albuminuria and glomerulosclerosis [121], but results in humans are not yet available. On the other hand, serotonin has also been studied, and 5-hydroxytryptamine receptor antagonist sarpogrelate, which is more known for its antiplatelet action, has also demonstrated renal anti-inflammatory and antiproteinuric effects $[122,123]$ and is undergoing a phase IV randomized control trial. Melanocortin receptor activation has been evaluated in several nondiabetic proteinuric glomerulopathies, and treatment with subcutaneous ACTH has also shown efficacy in reducing proteinuria in DKD [124].

Finally, reinforcement of endogenous mechanisms that are inherently protective against hyperglycemia-derived kidney damage has also been tried. For example, exogenous administration of the adipocytokine apelin $[125,126]$ or of activated protein $C$ [127] has renoprotective effects in DKD animals models. The exogenous activation of cannabinoid receptors has shown similar results $[128,129]$.

5.4. Antifibrotic and Anti-Inflammatory Agents. More downstream regulation of inflammatory and fibrosis cascades is also being explored. Treatments that inhibit cell adhesion and accumulation and cytokine production appear promising. In fact, TNF- $\alpha$ inhibition with infliximab or etanercept has been shown to decrease albuminuria and slow CKD progression in animal models, but further investigation in humans is required [130-132].

Transforming growth factor beta (TGF- $\beta$ ) blockade has been achieved through pirfenidone, currently approved for lung and liver fibrosis. Pilot studies showed a renal benefit but were halted due to adverse effects [133]. Tranilast, currently approved for allergic states and keloids, showed a reduction in albuminuria in a small pilot study with diabetic patients $[134,135]$, but never underwent a larger clinical trial. After promising experimental data, there are several ongoing studies to evaluate the efficacy of specific anti-TGF$\beta$ monoclonal antibodies, such as fresolimumab, in various proteinuric nephropathies $[136,137]$. Other TGF- $\beta$ blockers have been tested in animal models but have not yet arrived to human subjects [138-140].

Connective tissue growth factor (CTGF) has also been implied in the process of renal fibrosis in DKD. FG3019 is an anti-CTFG monoclonal antibody that showed albuminuria reduction in DKD [141] but has not been further investigated for this indication.

Reduction of chemokine production is also a potential treatment target in DKD. Several antagonists of the receptors CCR2 and CCR2/5 of the MCP-1 pathway (such as CCX 140B, TLK-19705, RS102895, PF-04634817, or BMS-813160) have shown positive experimental results and some of them are being evaluated in clinical trials [142-145].

Another important family of proteins is that of matrix metalloproteinases (MMPs), mainly involved in extracellular matrix regulation [146]. Molecules with capacity to inhibit MMPs, such as the antibiotic agents doxycycline and minocycline or the newer XL081 and XL874, were expected to have renoprotective effect, but when tested in humans, the impact was limited in magnitude and duration $[147,148]$. Some trials are still under way.

Finally, one of the newest therapeutic approaches is based on developing molecules that target microRNA (miRNA) pathways [149]. These small noncoding RNA fragments are involved in gene expression regulation, and many of them have been identified with both protective and pathogenic 
roles [150]. Growing knowledge in their functions triggers interest in developing new drugs to either silence pathogenic miRNAs (via anti-miRNA oligonucleotides or similar agents) or to enhance renoprotective miRNAs (with mimics, vectors, or exosomes). To date, only one oligonucleotide has been tested in diabetic mice to prove its renoprotective efficacy [151].

5.5. Other Agents. Hyperglycemia-derived advanced glycation end-products (AGE) are known to have a pathogenic effect through the activation of their receptor (RAGE), causing protein dysfunction and altered collagen turnover activating metalloproteinases $[152,153]$. Inhibition of RAGE with neutralizing antibodies reversed these pathogenic effects [154]. Several molecules that inhibit AGE formation, such as pimagedine or pyridoxamine, showed beneficial effects on animal models [155] but negative results or unacceptable adverse events in human trials [156-158].

Several oral adsorbents for uremic toxins have been tested, based on the hypothesis that reducing intestinal absorption of some of these toxins would diminish systemic inflammation and immune system activation. The most studied compound has been AST-120, also called kremezin, a spherical carbon preparation [159]. Initial studies cast hopeful results in early $\mathrm{CKD}[160,161]$, but randomized clinical trials in moderate-to-severe CKD showed no effect [162]. A recent meta-analysis that included both kremezin and other adsorbents from Asian origin like $\mathrm{Ai} \mathrm{Xi} \mathrm{Te}$ and Niaoduqing granted a possible benefit in slowing the speed of renal loss, but without clear evidence [163].

Finally, other approaches are still in earlier stages of investigation. These include infusion of endovenous mesenchymal precursor cells or modulation of immune response through regulatory $\mathrm{T}$ cells or autophagy [164-166].

Many other attempts have revealed unsuccessful, despite arriving to phase II or III, clinical trials. This has been the case of palosuran, a urotensin-II receptor antagonist [167], or sulodexide, a glycosaminoglycan with anti-inflammatory properties in animal models [168-170].

\section{Conflict of Interests}

The authors declare that there is no conflict of interests regarding the publication of this paper.

\section{Authors' Contribution}

Borja Quiroga and David Arroyo contributed equally.

\section{References}

[1] Centers for Disease Control and Prevention, Diabetes Report Card 2012, Department of Health and Human Services, Centers for Disease Control and Prevention, Atlanta, Ga, USA, 2012, http://www.cdc.gov/diabetes/pubs/pdf/diabetesreportcard.pdf.

[2] United States Renal Data System, 2014 Annual Data Report: Epidemiology of Kidney Disease in the United States, National Institutes of Health, National Institute of Diabetes and Digestive and
Kidney Diseases, Bethesda, Md, USA, 2014, http://www.usrds .org/2014/view/Default.aspx.

[3] J. E. Shaw, R. A. Sicree, and P. Z. Zimmet, "Global estimates of the prevalence of diabetes for 2010 and 2030," Diabetes Research and Clinical Practice, vol. 87, no. 1, pp. 4-14, 2010.

[4] A. X. Garg, B. A. Kiberd, W. F. Clark, R. B. Haynes, and C. M. Clase, "Albuminuria and renal insufficiency prevalence guides population screening: results from the NHANES III," Kidney International, vol. 61, no. 6, pp. 2165-2175, 2002.

[5] R. Retnakaran, C. A. Cull, K. I. Thorne, A. I. Adler, R. R. Holman, and UKPDS Study Group, "Risk factors for renal dysfunction in type 2 diabetes: U.K. Prospective Diabetes Study 74," Diabetes, vol. 55, no. 6, pp. 1832-1839, 2006.

[6] M. E. Molitch, M. Steffes, W. Sun et al., "Development and progression of renal insufficiency with and without albuminuria in adults with type 1 diabetes in the diabetes control and complications trial and the epidemiology of diabetes interventions and complications study," Diabetes Care, vol. 33, no. 7, pp. 1536-1543, 2010.

[7] A. S. Levey, D. Cattran, A. Friedman et al., "Proteinuria as a surrogate outcome in CKD: report of a scientific workshop sponsored by the National Kidney Foundation and the US Food and Drug Administration," American Journal of Kidney Diseases, vol. 54, no. 2, pp. 205-226, 2009.

[8] A. Thompson, "Proteinuria as a surrogate end point-more data are needed," Nature Reviews Nephrology, vol. 8, no. 5, pp. 306309, 2012.

[9] G. L. Bakris, "Recognition, pathogenesis, and treatment of different stages of nephropathy in patients with type 2 diabetes mellitus," Mayo Clinic Proceedings, vol. 86, no. 5, pp. 444-456, 2011.

[10] DCCT/EDIC Research Group, "Effect of intensive therapy on the development and progression of diabetic nephropathy in the Diabetes Control and Complications Trial," Kidney International, vol. 47, no. 6, pp. 1703-1720, 1995.

[11] DCCT/EDIC Research Group, "Retinopathy and nephropathy in patients with type 1 diabetes four years after a trial of intensive therapy. The diabetes control and complications trial/epidemiology of diabetes interventions and complications research group," The New England Journal of Medicine, vol. 342, no. 6, pp. 381-389, 2000.

[12] ADVANCE Collaborative Group, A. Patel, S. MacMahon et al., "Intensive blood glucose control and vascular outcomes in patients with type 2 diabetes," The New England Journal of Medicine, vol. 358, no. 24, pp. 2560-2572, 2008.

[13] The DCCT/EDIC Research Group, I. H. de Boer, W. Sun et al., "Intensive diabetes therapy and glomerular filtration rate in type 1 diabetes," The New England Journal of Medicine, vol. 365, no. 25, pp. 2366-2376, 2011.

[14] V. Perkovic, H. L. Heerspink, J. Chalmers et al., "Intensive glucose control improves kidney outcomes in patients with type 2 diabetes," Kidney International, vol. 83, no. 3, pp. 517-523, 2013.

[15] M. Daniels, S. N. Dubose, D. M. Maahs et al., "Factors associated with microalbuminuria in 7,549 children and adolescents with type 1 diabetes in the T1D exchange clinic registry," Diabetes Care, vol. 36, no. 9, pp. 2639-2645, 2013.

[16] I. H. de Boer and DCCT/EDIC Research Group, "Kidney disease and related findings in the diabetes control and complications trial/epidemiology of diabetes interventions and complications study," Diabetes Care, vol. 37, no. 1, pp. 24-30, 2014. 
[17] American Diabetes Association, "Standards of medical care in diabetes-2015," Diabetes Care, vol. 38, supplement 1, pp. S4S93, 2015.

[18] KDOQI, "KDOQI clinical practice guideline for diabetes and CKD: 2012 update," American Journal of Kidney Diseases, vol. 60, no. 5, pp. 850-886, 2012.

[19] P.-H. Groop, M. E. Cooper, V. Perkovic, A. Emser, H.-J. Woerle, and M. von Eynatten, "Linagliptin lowers albuminuria on top of recommended standard treatment in patients with type 2 diabetes and renal dysfunction," Diabetes Care, vol. 36, no. 11, pp. 3460-3468, 2013.

[20] H. Fujita, H. Taniai, H. Murayama et al., "DPP-4 inhibition with alogliptin on top of angiotensin II type 1 receptor blockade ameliorates albuminuria via up-regulation of SDF- $1 \alpha$ in type 2 diabetic patients with incipient nephropathy," Endocrine Journal, vol. 61, no. 2, pp. 159-166, 2014.

[21] M. Daniels, S. N. DuBose, D. M. Maahs et al., "KDOQI clinical practice guidelines and clinical practice recommendations for diabetes and chronic kidney disease," American Journal of Kidney Diseases, vol. 49, supplement 2, no. 2, pp. S12-S154, 2007.

[22] Kidney Disease: Improving Global Outcomes (KDIGO) Blood Pressure Work Group, "KDIGO clinical practice guideline for the management of blood pressure in chronic kidney disease," Kidney International Supplements, vol. 2, pp. 337-414, 2012.

[23] W. C. Cushman, G. W. Evans, R. P. Byington et al., "Effects of intensive blood-pressure control in type 2 diabetes mellitus," The New England Journal of Medicine, vol. 362, no. 17, pp. 1575$1585,2010$.

[24] H. Haller, S. Ito, J. L. Izzo Jr. et al., "Olmesartan for the delay or prevention of microalbuminuria in type 2 diabetes," The New England Journal of Medicine, vol. 364, no. 10, pp. 907-917, 2011.

[25] G. Eknoyan, "Obesity, diabetes, and chronic kidney disease," Current Diabetes Reports, vol. 7, no. 6, pp. 449-453, 2007.

[26] J. F. Briffa, A. J. Mcainch, P. Poronnik, and D. H. Hryciw, "Adipokines as a link between obesity and chronic kidney disease," The American Journal of Physiology-Renal Physiology, vol. 305, no. 12, pp. F1629-F1636, 2013.

[27] M. C. E. Rossi, A. Nicolucci, F. Pellegrini et al., "Obesity and changes in urine albumin/creatinine ratio in patients with type 2 diabetes: the DEMAND Study," Nutrition, Metabolism and Cardiovascular Diseases, vol. 20, no. 2, pp. 110-116, 2010.

[28] A. N. Friedman, M. Chambers, L. M. Kamendulis, and J. Temmerman, "Short-term changes after a weight reduction intervention in advanced diabetic nephropathy," Clinical Journal of the American Society of Nephrology, vol. 8, no. 11, pp. 18921898, 2013.

[29] E. Morales, M. A. Valero, M. León, E. Hernández, and M. Praga, "Beneficial effects of weight loss in overweight patients with chronic proteinuric nephropathies," American Journal of Kidney Diseases, vol. 41, no. 2, pp. 319-327, 2003.

[30] K. J. Neff, A. H. Frankel, F. W. K. Tam, D. M. Sadlier, C. Godson, and C. W. le Roux, "The effect of bariatric surgery on renal function and disease: a focus on outcomes and inflammation," Nephrology Dialysis Transplantation, vol. 28, supplement 4, pp. 73-82, 2013.

[31] B. L. Kasiske, J. D. A. Lakatua, J. Z. Ma, and T. A. Louis, "A metaanalysis of the effects of dietary protein restriction on the rate of decline in renal function," American Journal of Kidney Diseases, vol. 31, no. 6, pp. 954-961, 1998.

[32] L. T. J. Pijls, H. de Vries, A. J. M. Donker, and J. T. M. van Eijk, "The effect of protein restriction on albuminuria in patients with type 2 diabetes mellitus: a randomized trial," Nephrology Dialysis Transplantation, vol. 14, no. 6, pp. 1445-1453, 1999.

[33] H. P. Hansen, E. Tauber-Lassen, B. R. Jensen, and H.-H. Parving, "Effect of dietary protein restriction on prognosis in patients with diabetic nephropathy," Kidney International, vol. 62 , no. 1, pp. 220-228, 2002.

[34] M. Cignarelli, O. Lamacchia, S. di Paolo, and L. Gesualdo, "Cigarette smoking and kidney dysfunction in diabetes mellitus," Journal of Nephrology, vol. 21, no. 2, pp. 180-189, 2008.

[35] T. Chuahirun, J. Simoni, C. Hudson et al., "Cigarette smoking exacerbates and its cessation ameliorates renal injury in type 2 diabetes," American Journal of the Medical Sciences, vol. 327, no. 2, pp. 57-67, 2004.

[36] K. Phisitkul, K. Hegazy, T. Chuahirun et al., "Continued smoking exacerbates but cessation ameliorates progression of early type 2 diabetic nephropathy," The American Journal of the Medical Sciences, vol. 335, no. 4, pp. 284-291, 2008.

[37] D. de Zeeuw, G. Remuzzi, H.-H. Parving et al., "Proteinuria, a target for renoprotection in patients with type 2 diabetic nephropathy: lessons from RENAAL," Kidney International, vol. 65, no. 6, pp. 2309-2320, 2004.

[38] E. J. Lewis, L. G. Hunsicker, W. R. Clarke et al., "Renoprotective effect of the angiotensin-receptor antagonist irbesartan in patients with nephropathy due to type 2 diabetes," The New England Journal of Medicine, vol. 345, no. 12, pp. 851-860, 2001.

[39] G. Viberti, C. E. Mogensen, L. C. Groop, and J. F. Pauls, "Effect of captopril on progression to clinical proteinuria in patients with insulin-dependent diabetes mellitus and microalbuminuria. European Microalbuminuria Captopril Study Group," Journal of the American Medical Association, vol. 271, no. 4, pp. 275-279, 1994.

[40] L. M. B. Laffel, J. B. McGill, and D. J. Gans, “The beneficial effect of angiotensin-converting enzyme inhibition with captopril on diabetic nephropathy in normotensive IDDM patients with microalbuminuria," The American Journal of Medicine, vol. 99, no. 5, pp. 497-504, 1995.

[41] L. F. Fried, N. Emanuele, J. H. Zhang et al., "Combined angiotensin inhibition for the treatment of diabetic nephropathy," The New England Journal of Medicine, vol. 369, no. 20, pp. 1892-1903, 2013.

[42] G. Fernandez Juarez, J. Luño, V. Barrio et al., "Effect of dual blockade of the renin-angiotensin system on the progression of type 2 diabetic nephropathy: a randomized trial," American Journal of Kidney Diseases, vol. 61, no. 2, pp. 211-218, 2013.

[43] ONTARGET Investigators, S. Yusuf, K. K. Teo et al., "Telmisartan, ramipril, or both in patients at high risk for vascular events," The New England Journal of Medicine, vol. 358, no. 15, pp. 15471559, 2008.

[44] L. Tylicki, A. Jakubowska, S. Lizakowski, D. Swietlik, and B. Rutkowski, "Management of renin-angiotensin system blockade in patients with chronic kidney disease under specialist care. Retrospective cross-sectional study," Journal of the ReninAngiotensin-Aldosterone System, 2014.

[45] H.-H. Parving, B. M. Brenner, J. J. V. McMurray et al., "Cardiorenal end points in a trial of aliskiren for type 2 diabetes," The New England Journal of Medicine, vol. 367, no. 23, pp. 22042213, 2012.

[46] H.-H. Parving, F. Persson, J. B. Lewis, E. J. Lewis, and N. K. Hollenberg, "Aliskiren combined with losartan in type 2 diabetes and nephropathy," The New England Journal of Medicine, vol. 358, no. 23, pp. 2433-2446, 2008. 
[47] A. Sato, K. Hayashi, M. Naruse, and T. Saruta, "Effectiveness of aldosterone blockade in patients with diabetic nephropathy," Hypertension, vol. 41, no. 1, pp. 64-68, 2003.

[48] A. Esteghamati, S. Noshad, S. Jarrah, M. Mousavizadeh, S. H. Khoee, and M. Nakhjavani, "Long-term effects of addition of mineralocorticoid receptor antagonist to angiotensin II receptor blocker in patients with diabetic nephropathy: a randomized clinical trial," Nephrology Dialysis Transplantation, vol. 28, no. 11, pp. 2823-2833, 2013.

[49] M. Epstein, G. H. Williams, M. Weinberger et al., "Selective aldosterone blockade with eplerenone reduces albuminuria in patients with type 2 diabetes," Clinical journal of the American Society of Nephrology, vol. 1, no. 5, pp. 940-951, 2006.

[50] P. Susantitaphong, K. Sewaralthahab, E. M. Balk, S. Eiam-Ong, N. E. Madias, and B. L. Jaber, "Efficacy and safety of combined vs. single renin-angiotensin-aldosterone system blockade in chronic kidney disease: a meta-analysis," American Journal of Hypertension, vol. 26, no. 3, pp. 424-441, 2013.

[51] F. F. Hou, D. Xie, X. Zhang et al., "Renoprotection of Optimal Antiproteinuric Doses (ROAD) study: a randomized controlled study of benazepril and losartan in chronic renal insufficiency," Journal of the American Society of Nephrology, vol. 18, no. 6, pp. 1889-1898, 2007.

[52] P. Ruggenenti, A. Fassi, A. P. Ilieva et al., "Preventing microalbuminuria in type 2 diabetes," The New England Journal of Medicine, vol. 351, no. 19, pp. 1941-1951, 2004.

[53] J. Lv, V. Perkovic, C. V. Foote, M. E. Craig, J. C. Craig, and G. F. M. Strippoli, "Antihypertensive agents for preventing diabetic kidney disease.," Cochrane Database of Systematic Reviews, no. 12, Article ID CD004136, 2012.

[54] M. G. Saklayen, L. K. Gyebi, J. Tasosa, and J. Yap, "Effects of additive therapy with spironolactone on proteinuria in diabetic patients already on ACE inhibitor or ARB therapy: results of a randomized, placebo-controlled, double-blind, crossover trial," Journal of Investigative Medicine, vol. 56, no. 4, pp. 714-719, 2008.

[55] M. B. Davidson, A. Wong, A. H. Hamrahian, M. Stevens, and E. S. Siraj, "Effect of spironolactone therapy on albuminuria in patients with type 2 diabetes treated with angiotensinconverting enzyme inhibitors," Endocrine Practice, vol. 14, no. 8, pp. 985-992, 2008.

[56] U. F. Mehdi, B. Adams-Huet, P. Raskin, G. L. Vega, and R. D. Toto, "Addition of angiotensin receptor blockade or mineralocorticoid antagonism to maximal angiotensin-converting enzyme inhibition in diabetic nephropathy," Journal of the American Society of Nephrology, vol. 20, no. 12, pp. 2641-2650, 2009.

[57] S. Bianchi, R. Bigazzi, and V. M. Campese, "Long-term effects of spironolactone on proteinuria and kidney function in patients with chronic kidney disease," Kidney International, vol. 70, no. 12, pp. 2116-2123, 2006.

[58] E. Morales, V. G. Millet, J. Rojas-Rivera et al., "Renoprotective effects of mineralocorticoid receptor blockers in patients with proteinuric kidney diseases," Nephrology Dialysis Transplantation, vol. 28, no. 2, pp. 405-412, 2013.

[59] B. Pitt, F. Zannad, W. J. Remme et al., "The effect of spironolactone on morbidity and mortality in patients with severe heart failure," The New England Journal of Medicine, vol. 341, no. 10, pp. 709-717, 1999.
[60] B. Fernandez-Fernandez, A. Ortiz, C. Gomez-Guerrero, and J. Egido, "Therapeutic approaches to diabetic nephropathybeyond the RAS," Nature Reviews Nephrology, vol. 10, no. 6, pp. 325-346, 2014.

[61] H. Zheng, S. A. Whitman, W. Wu et al., "Therapeutic potential of Nrf2 activators in streptozotocin-induced diabetic nephropathy," Diabetes, vol. 60, no. 11, pp. 3055-3066, 2011.

[62] K. Yoh, A. Hirayama, K. Ishizaki et al., "Hyperglycemia induces oxidative and nitrosative stress and increases renal functional impairment in Nrf2-deficient mice," Genes to Cells, vol. 13, no. 11, pp. 1159-1170, 2008.

[63] P. E. Pergola, P. Raskin, R. D. Toto et al., "Bardoxolone methyl and kidney function in CKD with type 2 diabetes," The New England Journal of Medicine, vol. 365, no. 4, pp. 327-336, 2011.

[64] D. de Zeeuw, T. Akizawa, P. Audhya et al., "Bardoxolone methyl in type 2 diabetes and stage 4 chronic kidney disease," The New England Journal of Medicine, vol. 369, no. 26, pp. 2492-2503, 2013.

[65] S. M. Tan, A. Sharma, N. Stefanovic et al., "Derivative of bardoxolone methyl, dh404, in an inverse dose-dependent manner lessens diabetes-associated atherosclerosis and improves diabetic kidney disease," Diabetes, vol. 63, no. 9, pp. 3091-3103, 2014.

[66] G. Fernández-Juárez, J. Luño, V. Barrio et al., “25 (OH) vitamin $\mathrm{D}$ levels and renal disease progression in patients with type 2 diabetic nephropathy and blockade of the renin-angiotensin system," Clinical Journal of the American Society of Nephrology, vol. 8, no. 11, pp. 1870-1876, 2013.

[67] D. L. Andress, "Vitamin D in chronic kidney disease: a systemic role for selective vitamin D receptor activation," Kidney International, vol. 69, no. 1, pp. 33-43, 2006.

[68] R. Agarwal, M. Acharya, J. Tian et al., "Antiproteinuric effect of oral paricalcitol in chronic kidney disease," Kidney International, vol. 68, no. 6, pp. 2823-2828, 2005.

[69] D. de Zeeuw, R. Agarwal, M. Amdahl et al., "Selective vitamin D receptor activation with paricalcitol for reduction of albuminuria in patients with type 2 diabetes (VITAL study): a randomised controlled trial," The Lancet, vol. 376, no. 9752, pp. 1543-1551, 2010.

[70] H. J. Lambers Heerspink, R. Agarwal, D. W. Coyne et al., “The selective vitamin $\mathrm{D}$ receptor activator for albuminuria lowering (VITAL) study: study design and baseline characteristics," The American Journal of Nephrology, vol. 30, no. 3, pp. 280-286, 2009.

[71] Z. Eren, M. Y. Günal, E. A. Bakir et al., "Effects of paricalcitol and aliskiren combination therapy on experimental diabetic nephropathy model in rats," Kidney and Blood Pressure Research, vol. 39, no. 6, pp. 581-590, 2014.

[72] M. H. de Borst, R. Hajhosseiny, H. Tamez, J. Wenger, R. Thadhani, and D. J. A. Goldsmith, "Active vitamin D treatment for reduction of residual proteinuria: a systematic review," Journal of the American Society of Nephrology, vol. 24, no. 11, pp. 1863-1871, 2013.

[73] N. K. Agrawal and S. Kant, "Targeting inflammation in diabetes: newer therapeutic options," World Journal of Diabetes, vol. 5, no. 5, pp. 697-710, 2014.

[74] M. Rodríguez-Morán, G. González-González, M. V. BermúdezBarba et al., "Effects of pentoxifylline on the urinary protein excretion profile of type 2 diabetic patients with microproteinuria-a double-blind, placebo-controlled randomized trial," Clinical Nephrology, vol. 66, no. 1, pp. 3-10, 2006. 
[75] J. F. Navarro-González, C. Mora-Fernández, M. Muros de Fuentes et al., "Effect of pentoxifylline on renal function and urinary albumin excretion in patients with diabetic kidney disease: the PREDIAN trial," Journal of the American Society of Nephrology, vol. 26, no. 1, pp. 220-229, 2015.

[76] M. Goicoechea, S. G. de Vinuesa, B. Quiroga et al., "Effects of pentoxifylline on inflammatory parameters in chronic kidney disease patients: a randomized trial," Journal of Nephrology, vol. 25, no. 6, pp. 969-975, 2012.

[77] F. P. Brouwers, F. W. Asselbergs, H. L. Hillege et al., "Long-term effects of fosinopril and pravastatin on cardiovascular events in subjects with microalbuminuria: ten years of follow-up of Prevention of Renal and Vascular End-stage Disease Intervention Trial (PREVEND IT)," The American Heart Journal, vol. 161, no. 6, pp. 1171-1178, 2011.

[78] S. J. Shah, D. D. Waters, P. Barter et al., "Intensive lipidlowering with atorvastatin for secondaryprevention in patients after coronary artery bypass surgery," Journal of the American College of Cardiology, vol. 51, no. 20, pp. 1938-1943, 2008.

[79] W. Lieberthal and J. S. Levine, "The role of the mammalian target of rapamycin (mTOR) in renal disease," Journal of the American Society of Nephrology, vol. 20, no. 12, pp. 2493-2502, 2009.

[80] A. H. Hopper, H. Tindall, and J. A. Davies, "Administration of aspirin-dipyridamole reduces proteinuria in diabetic nephropathy," Nephrology Dialysis Transplantation, vol. 4, no. 2, pp. 140$143,1989$.

[81] J. Rodriguez-Vita, M. Ruiz-Ortega, M. Rupérez et al., "Endothelin-1, via ETA receptor and independently of transforming growth factor- $\beta$, increases the connective tissue growth factor in vascular smooth muscle cells," Circulation Research, vol. 97, no. 2, pp. 125-134, 2005.

[82] D. E. Kohan and D. M. Pollock, "Endothelin antagonists for diabetic and non-diabetic chronic kidney disease," British Journal of Clinical Pharmacology, vol. 76, no. 4, pp. 573-579, 2013.

[83] D. Gómez-Garre, R. Largo, X.-H. Liu et al., "An orally active $\mathrm{ET}_{A} / \mathrm{ET}_{B}$ receptor antagonist ameliorates proteinuria and glomerular lesions in rats with proliferative nephritis," Kidney International, vol. 50, no. 3, pp. 962-972, 1996.

[84] D. E. Kohan, J. G. Cleland, L. J. Rubin, D. Theodorescu, and M. Barton, "Clinical trials with endothelin receptor antagonists: what went wrong and where can we improve?" Life Sciences, vol. 91, no. 13-14, pp. 528-539, 2012.

[85] J. F. E. Mann, D. Green, K. Jamerson et al., "Avosentan for overt diabetic nephropathy," Journal of the American Society of Nephrology, vol. 21, no. 3, pp. 527-535, 2010.

[86] D. L. Andress, B. Coll, Y. Pritchett, J. Brennan, M. Molitch, and D. E. Kohan, "Clinical efficacy of the selective endothelin A receptor antagonist, atrasentan, in patients with diabetes and chronic kidney disease (CKD)," Life Sciences, vol. 91, no. 13-14, pp. 739-742, 2012.

[87] K. Winiarska, K. Szymanski, P. Gorniak, M. Dudziak, and J. Bryla, "Hypoglycaemic, antioxidative and nephroprotective effects of taurine in alloxan diabetic rabbits," Biochimie, vol. 91, no. 2, pp. 261-270, 2009.

[88] G. G. Wang, X. H. Lu, W. Li, X. Zhao, and C. Zhang, "Protective effects of luteolin on diabetic nephropathy in STZ-induced diabetic rats," Evidence-Based Complementary and Alternative Medicine, vol. 2011, Article ID 323171, 7 pages, 2011.
[89] S. Bhattacharya, P. Manna, R. Gachhui, and P. C. Sil, "DSaccharic acid 1,4-lactone protects diabetic rat kidney by ameliorating hyperglycemia-mediated oxidative stress and renal inflammatory cytokines via NF- $\kappa \mathrm{B}$ and PKC signaling," Toxicology and Applied Pharmacology, vol. 267, no. 1, pp. 16-29, 2013.

[90] K. Khazim, Y. Gorin, R. C. Cavaglieri, H. E. Abboud, and P. Fanti, "The antioxidant silybin prevents high glucose-induced oxidative stress and podocyte injury in vitro and in vivo," American Journal of Physiology - Renal Physiology, vol. 305, no. 5, pp. F691-F700, 2013.

[91] J. F. Ndisang and A. Jadhav, "Hemin therapy improves kidney function in male streptozotocin-induced diabetic rats: role of the heme oxygenase/atrial natriuretic peptide/adiponectin axis," Endocrinology, vol. 155, no. 1, pp. 215-229, 2014.

[92] Z. Sun, Q. Fu, L. Cao, W. Jin, L. Cheng, and Z. Li, "Intravenous $N$-acetylcysteine for prevention of contrast-induced nephropathy: a meta-analysis of randomized, controlled trials," PLoS ONE, vol. 8, no. 1, Article ID e55124, 2013.

[93] M. K. Fallahzadeh, B. Dormanesh, M. M. Sagheb et al., "Effect of addition of silymarin to renin-angiotensin system inhibitors on proteinuria in type 2 diabetic patients with overt nephropathy: a randomized, double-blind, placebo-controlled trial," American Journal of Kidney Diseases, vol. 60, no. 6, pp. 896-903, 2012.

[94] S. R. Hashemi, H. Noshad, A. Tabrizi et al., "Angiotensin receptor blocker and $\mathrm{N}$-acetyl cysteine for reduction of proteinuria in patients with type 2 diabetes mellitus," Iranian Journal of Kidney Diseases, vol. 6, no. 1, pp. 39-43, 2012.

[95] K. Endo, A. Saiki, T. Yamaguchi et al., "Probucol suppresses initiation of chronic hemodialysis therapy and renal dysfunctionrelated death in diabetic nephropathy patients: Sakura Study," Journal of Atherosclerosis and Thrombosis, vol. 20, no. 5, pp. 494502, 2013.

[96] Y.-P. Siu, K.-T. Leung, M. K.-H. Tong, and T.-H. Kwan, "Use of allopurinol in slowing the progression of renal disease through its ability to lower serum uric acid level," American Journal of Kidney Diseases, vol. 47, no. 1, pp. 51-59, 2006.

[97] M. Goicoechea, S. G. de Vinuesa, U. Verdalles et al., "Effect of allopurinol in chronic kidney disease progression and cardiovascular risk," Clinical Journal of the American Society of Nephrology, vol. 5, no. 8, pp. 1388-1393, 2010.

[98] D. M. Maahs, L. Caramori, D. Z. I. Cherney et al., "Uric acid lowering to prevent kidney function loss in diabetes: the preventing early renal function loss (PERL) allopurinol study," Current Diabetes Reports, vol. 13, no. 4, pp. 550-559, 2013.

[99] T. Hosoya, K. Kimura, S. Itoh et al., "The effect of febuxostat to prevent a further reduction in renal function of patients with hyperuricemia who have never had gout and are complicated by chronic kidney disease stage 3: study protocol for a multicenter randomized controlled study," Trials, vol. 15, no. 1, article 26, 2014.

[100] S. Budhiraja and J. Singh, "Protein kinase C beta inhibitors: a new therapeutic target for diabetic nephropathy and vascular complications," Fundamental and Clinical Pharmacology, vol. 22, no. 3, pp. 231-240, 2008.

[101] D. Bansal, Y. Badhan, K. Gudala, and F. Schifano, "Ruboxistaurin for the treatment of diabetic peripheral neuropathy: a systematic review of randomized clinical trials," Diabetes \& Metabolism Journal, vol. 37, no. 5, pp. 375-384, 2013.

[102] M. J. Sheetz, L. P. Aiello, M. D. Davis et al., "The effect of the Oral PKC $\beta$ inhibitor ruboxistaurin on vision loss in two phase 3 studies," Investigative Ophthalmology and Visual Science, vol. 54, no. 3, pp. 1750-1757, 2013. 
[103] K. R. Tuttle, J. B. McGill, D. J. Haney, T. E. Lin, and P. W. Anderson, "Kidney outcomes in long-term studies of ruboxistaurin for diabetic eye disease," Clinical Journal of the American Society of Nephrology, vol. 2, no. 4, pp. 631-636, 2007.

[104] K. R. Tuttle, G. L. Bakris, R. D. Toto, J. B. McGill, K. Hu, and P. W. Anderson, "The effect of ruboxistaurin on nephropathy in type 2 diabetes," Diabetes Care, vol. 28, no. 11, pp. 2686-2690, 2005.

[105] K. R. Tuttle, J. B. McGill, E. J. Bastyr III, K. K. Poi, N. Shahri, and P. W. Anderson, "Effect of ruboxistaurin on albuminuria and estimated GFR in people with diabetic peripheral neuropathy: results from a randomized trial," American Journal of Kidney Diseases, vol. 65, no. 4, pp. 634-636, 2015.

[106] M. Lassila, K. Jandeleit-Dahm, K. K. Seah et al., "Imatinib attenuates diabetic nephropathy in apolipoprotein E-knockout mice," Journal of the American Society of Nephrology, vol. 16, no. 2, pp. 367-373, 2005.

[107] M. Iyoda, T. Shibata, Y. Hirai, Y. Kuno, and T. Akizawa, "Nilotinib attenuates renal injury and prolongs survival in chronic kidney disease," Journal of the American Society of Nephrology, vol. 22, no. 8, pp. 1486-1496, 2011.

[108] M. J. Kim and Y. Lim, "Protective effect of short-term genistein supplementation on the early stage in diabetes-induced renal damage," Mediators of Inflammation, vol. 2013, Article ID 510212, 14 pages, 2013.

[109] K. Taniguchi, L. Xia, H. J. Goldberg et al., "Inhibition of src kinase blocks high glucose-induced EGFR transactivation and collagen synthesis in mesangial cells and prevents diabetic nephropathy in mice," Diabetes, vol. 62, no. 11, pp. 3874-3886, 2013.

[110] V. Kolavennu, L. Zeng, H. Peng, Y. Wang, and F. R. Danesh, "Targeting of RhoA/ROCK signaling ameliorates progression of diabetic nephropathy independent of glucose control," Diabetes, vol. 57, no. 3, pp. 714-723, 2008.

[111] R. Komers, "Rho kinase inhibition in diabetic kidney disease," British Journal of Clinical Pharmacology, vol. 76, no. 4, pp. 551559, 2013.

[112] L. Gu, Q. Gao, L. Ni, M. Wang, and F. Shen, "Fasudil inhibits epithelial-myofibroblast transdifferentiation of human renal tubular epithelial HK-2 cells induced by high glucose," Chemical and Pharmaceutical Bulletin, vol. 61, no. 7, pp. 688-694, 2013.

[113] D.-S. Jung, J. J. Li, S.-J. Kwak et al., "FR167653 inhibits fibronectin expression and apoptosis in diabetic glomeruli and in high-glucose-stimulated mesangial cells," American Journal of Physiology-Renal Physiology, vol. 295, no. 2, pp. F595-F604, 2008.

[114] N. Sugiyama, M. Kohno, and T. Yokoyama, "Inhibition of the p38 MAPK pathway ameliorates renal fibrosis in an NPHP2 mouse model," Nephrology Dialysis Transplantation, vol. 27, no. 4, pp. 1351-1358, 2012.

[115] S.-H. Kim, Y.-W. Jang, P. Hwang, H.-J. Kim, G.-Y. Han, and C.-W. Kim, "The reno-protective effect of a phosphoinositide 3-kinase inhibitor wortmannin on streptozotocin-induced proteinuric renal disease rats," Experimental and Molecular Medicine, vol. 44, no. 1, pp. 45-51, 2012.

[116] C. A. Durand, M. J. Richer, K. Brenker et al., "Selective pharmacological inhibition of phosphoinositide 3-kinase p110delta opposes the progression of autoimmune diabetes in non-obese diabetic (NOD) mice," Autoimmunity, vol. 46, no. 1, pp. 62-73, 2013.

[117] I. I. Shemesh, B. Rozen-Zvi, Y. Kalechman, U. Gafter, B. Sredni, and G. Drossopoulou, "AS101 prevents diabetic nephropathy progression and mesangial cell dysfunction: regulation of the AKT downstream pathway," PLoS ONE, vol. 9, no. 12, 2014.

[118] H. Sugimoto, V. S. LeBleu, D. Bosukonda et al., "Activin-like kinase 3 is important for kidney regeneration and reversal of fibrosis," Nature Medicine, vol. 18, no. 3, pp. 396-404, 2012.

[119] F. C. Brosius III and J. C. He, "JAK inhibition and progressive kidney disease," Current Opinion in Nephrology and Hypertension, vol. 24, no. 1, pp. 88-95, 2015.

[120] G. Ortiz-Muñoz, V. Lopez-Parra, O. Lopez-Franco et al., "Suppressors of cytokine signaling abrogate diabetic nephropathy," Journal of the American Society of Nephrology, vol. 21, no. 5, pp. 763-772, 2010.

[121] M.-L. P. Gross, A. Koch, B. Mühlbauer et al., "Renoprotective effect of a dopamine D3 receptor antagonist in experimental type II diabetes," Laboratory Investigation, vol. 86, no. 3, pp. 262274, 2006.

[122] T. Takahashi, M. Yano, J. Minami et al., "Sarpogrelate hydrochloride, a serotonin $2 \mathrm{~A}$ receptor antagonist, reduces albuminuria in diabetic patients with early-stage diabetic nephropathy," Diabetes Research and Clinical Practice, vol. 58, no. 2, pp. 123-129, 2002.

[123] S. Ogawa, T. Mori, K. Nako, T. Ishizuka, and S. Ito, "Reduced albuminuria with sarpogrelate is accompanied by a decrease in monocyte chemoattractant protein-1 levels in type 2 diabetes," Clinical Journal of the American Society of Nephrology, vol. 3, no. 2, pp. 362-368, 2008.

[124] J. A. Tumlin, C. M. Galphin, and B. H. Rovin, "Advanced diabetic nephropathy with nephrotic range proteinuria: a pilot study of the long-term efficacy of subcutaneous ACTH gel on proteinuria, progression of CKD, and urinary levels of VEGF and MCP-1," Journal of Diabetes Research, vol. 2013, Article ID 489869, 8 pages, 2013.

[125] R. T. Day, R. C. Cavaglieri, and D. Feliers, "Apelin retards the progression of diabetic nephropathy," The American Journal of Physiology-Renal Physiology, vol. 304, no. 6, pp. F788-F800, 2013.

[126] H. Chen, J. Li, L. Jiao et al., "Apelin inhibits the development of diabetic nephropathy by regulating histone acetylation in Akita mouse," The Journal of Physiology, vol. 592, part 3, pp. 505-521, 2014.

[127] P. Gil-Bernabe, C. N. D’Alessandro-Gabazza, M. Toda et al., "Exogenous activated protein $\mathrm{C}$ inhibits the progression of diabetic nephropathy," Journal of Thrombosis and Haemostasis, vol. 10, no. 3, pp. 337-346, 2012.

[128] F. Barutta, F. Piscitelli, S. Pinach et al., "Protective role of cannabinoid receptor type 2 in a mouse model of diabetic nephropathy," Diabetes, vol. 60, no. 9, pp. 2386-2396, 2011.

[129] D. H. Nam, M. H. Lee, J. E. Kim et al., "Blockade of cannabinoid receptor 1 improves insulin resistance, lipid metabolism, and diabetic nephropathy in db/db mice," Endocrinology, vol. 153, no. 3, pp. 1387-1396, 2012.

[130] A. Doria, M. A. Niewczas, and P. Fiorina, "Can existing drugs approved for other indications retard renal function decline in patients with type 1 diabetes and nephropathy?" Seminars in Nephrology, vol. 32, no. 5, pp. 437-444, 2012.

[131] Y. Moriwaki, T. Inokuchi, A. Yamamoto et al., "Effect of TNFalpha inhibition on urinary albumin excretion in experimental diabetic rats," Acta Diabetologica, vol. 44, no. 4, pp. 215-218, 2007.

[132] K. Omote, T. Gohda, M. Murakoshi et al., "Role of the TNF pathway in the progression of diabetic nephropathy in KK-Ay 
mice," The American Journal of Physiology-Renal Physiology, vol. 306, no. 11, pp. F1335-F1347, 2014.

[133] K. Sharma, J. H. Ix, A. V. Mathew et al., "Pirfenidone for diabetic nephropathy," Journal of the American Society of Nephrology, vol. 22, no. 6, pp. 1144-1151, 2011.

[134] H. Akahori, T. Ota, M. Torita, H. Ando, S. Kaneko, and T. Takamura, "Tranilast prevents the progression of experimental diabetic nephropathy through suppression of enhanced extracellular matrix gene expression," Journal of Pharmacology and Experimental Therapeutics, vol. 314, no. 2, pp. 514-521, 2005.

[135] J. Soma, K. Sato, H. Saito, and Y. Tsuchiya, "Effect of tranilast in early-stage diabetic nephropathy," Nephrology Dialysis Transplantation, vol. 21, no. 10, pp. 2795-2799, 2006.

[136] F. N. Ziyadeh, "Different roles for TGF-beta and VEGF in the pathogenesis of the cardinal features of diabetic nephropathy," Diabetes Research and Clinical Practice, vol. 82, supplement 1, pp. S38-S41, 2008.

[137] H. Trachtman, F. C. Fervenza, D. S. Gipson et al., "A phase 1, single-dose study of fresolimumab, an anti-TGF- $\beta$ antibody, in treatment-resistant primary focal segmental glomerulosclerosis," Kidney International, vol. 79, no. 11, pp. 1236-1243, 2011.

[138] H. S. Jeong, K. K. Park, S. P. Kim, I. J. Choi, I. K. Lee, and H. C. Kim, "Effect of antisense TGF- $\beta 1$ oligodeoxynucleotides in streptozotocin-induced diabetic rat kidney," Journal of Korean Medical Science, vol. 19, no. 3, pp. 374-383, 2004.

[139] L. M. Russo, E. del Re, D. Brown, and H. Y. Lin, "Evidence for a role of transforming growth factor (TGF)-betal in the induction of postglomerular albuminuria in diabetic nephropathy: amelioration by soluble TGF-beta type II receptor," Diabetes, vol. 56, no. 2, pp. 380-388, 2007.

[140] G. Castoldi, C. R. T. di Gioia, C. Bombardi et al., "Renal antifibrotic effect of n-acetyl-seryl-aspartyl-lysyl-proline in diabetic rats," The American Journal of Nephrology, vol. 37, no. 1, pp. 6473, 2013.

[141] S. G. Adler, S. Schwartz, M. E. Williams et al., "Phase 1 study of anti-CTGF monoclonal antibody in patients with diabetes and microalbuminuria," Clinical Journal of the American Society of Nephrology, vol. 5, no. 8, pp. 1420-1428, 2010.

[142] J. A. Moreno, S. Moreno, A. Rubio-Navarro et al., "Targeting chemokines in proteinuria-induced renal disease," Expert Opinion on Therapeutic Targets, vol. 16, no. 8, pp. 833-845, 2012.

[143] M. Okamoto, M. Fuchigami, T. Suzuki, and N. Watanabe, "A novel $\mathrm{C}-\mathrm{C}$ chemokine receptor 2 antagonist prevents progression of albuminuria and atherosclerosis in mouse models," Biological and Pharmaceutical Bulletin, vol. 35, no. 11, pp. 20692074, 2012.

[144] S. J. Seok, E. S. Lee, G. T. Kim et al., "Blockade of CCL2/CCR2 signalling ameliorates diabetic nephropathy in $d b / d b$ mice," Nephrology Dialysis Transplantation, vol. 28, no. 7, pp. 17001710, 2013.

[145] T. Sullivan, Z. Miao, D. J. Dairaghi et al., "CCR2 antagonist CCX140-B provides renal and glycemic benefits in diabetic transgenic human CCR2 knockin mice," The American Journal of Physiology-Renal Physiology, vol. 305, no. 9, pp. F1288F1297, 2013.

[146] R. J. Tan and Y. Liu, "Matrix metalloproteinases in kidney homeostasis and diseases," The American Journal of PhysiologyRenal Physiology, vol. 302, no. 11, pp. F1351-F1361, 2012.

[147] H. K. Aggarwal, D. Jain, P. Talapatra, R. K. Yadav, T. Gupta, and K. L. Kathuria, "Evaluation of role of doxycycline (a matrix metalloproteinase inhibitor) on renal functions in patients of diabetic nephropathy," Renal Failure, vol. 32, no. 8, pp. 941-946, 2010.

[148] J. M. Williams, J. Zhang, P. North et al., "Evaluation of metalloprotease inhibitors on hypertension and diabetic nephropathy," The American Journal of Physiology —Renal Physiology, vol. 300, no. 4, pp. F983-F998, 2011.

[149] P. Trionfini, A. Benigni, and G. Remuzzi, "MicroRNAs in kidney physiology and disease," Nature Reviews Nephrology, vol. 11, no. 1, pp. 23-33, 2014.

[150] H. Wu, L. Kong, S. Zhou et al., "The role of microRNAs in diabetic nephropathy," Journal of Diabetes Research, vol. 2014, Article ID 920134, 12 pages, 2014.

[151] S. Putta, L. Lanting, G. Sun, G. Lawson, M. Kato, and R. Natarajan, "Inhibiting microRNA-192 ameliorates renal fibrosis in diabetic nephropathy," Journal of the American Society of Nephrology, vol. 23, no. 3, pp. 458-469, 2012.

[152] R. Ramasamy, S. F. Yan, and A. M. Schmidt, "The diverse ligand repertoire of the receptor for advanced glycation endproducts and pathways to the complications of diabetes," Vascular Pharmacology, vol. 57, no. 5-6, pp. 160-167, 2012.

[153] A. I. Serban, L. Stanca, O. I. Geicu, M. C. Munteanu, M. Costache, and A. Dinischiotu, "Extracellular matrix is modulated in advanced glycation end products milieu via a RAGE receptor dependent pathway boosted by transforming growth factor- $\beta 1$ RAGE- $\beta 1$," Journal of Diabetes, vol. 7, no. 1, pp. 114124, 2015.

[154] A. Flyvbjerg, L. Denner, B. F. Schrijvers et al., "Long-term renal effects of a neutralizing RAGE antibody in obese type 2 diabetic mice," Diabetes, vol. 53, no. 1, pp. 166-172, 2004.

[155] J. H. Kim, C. O. Hong, Y. C. Koo, S. J. Kim, and K. W. Lee, "Oral administration of ethyl acetate-soluble portion of Terminalia chebula conferring protection from streptozotocininduced diabetic mellitus and its complications," Biological and Pharmaceutical Bulletin, vol. 34, no. 11, pp. 1702-1709, 2011.

[156] W. K. Bolton, D. C. Cattran, M. E. Williams et al., "Randomized trial of an inhibitor of formation of advanced glycation end products in diabetic nephropathy," American Journal of Nephrology, vol. 24, no. 1, pp. 32-40, 2004.

[157] M. E. Williams, W. K. Bolton, R. G. Khalifah, T. P. Degenhardt, R. J. Schotzinger, and J. B. McGill, "Effects of pyridoxamine in combined phase 2 studies of patients with type 1 and type 2 diabetes and overt nephropathy," American Journal of Nephrology, vol. 27, no. 6, pp. 605-614, 2007.

[158] E. J. Lewis, T. Greene, S. Spitalewiz et al., "Pyridorin in type 2 diabetic nephropathy," Journal of the American Society of Nephrology, vol. 23, no. 1, pp. 131-136, 2012.

[159] G. Schulman, R. Vanholder, and T. Niwa, "AST-120 for the management of progression of chronic kidney disease," International Journal of Nephrology and Renovascular Disease, vol. 7, pp. 49$56,2014$.

[160] T. Sanaka, T. Akizawa, K. Koide, and S. Koshikawa, "Protective effect of an oral adsorbent on renal function in chronic renal failure: determinants of its efficacy in diabetic nephropathy," Therapeutic Apheresis and Dialysis, vol. 8, no. 3, pp. 232-240, 2004.

[161] K. Konishi, S. Nakano, S.-I. Tsuda, A. Nakagawa, T. Kigoshi, and D. Koya, "AST-120 (Kremezin) initiated in early stage chronic kidney disease stunts the progression of renal dysfunction in type 2 diabetic subjects," Diabetes Research and Clinical Practice, vol. 81, no. 3, pp. 310-315, 2008. 
[162] G. Schulman, T. Berl, G. J. Beck et al., "Randomized placebocontrolled EPPIC trials of AST-120 in CKD," Journal of the American Society of Nephrology, 2014.

[163] H. M. Wu, H. J. Sun, F. Wang, M. Yang, B. R. Dong, and G. J. Liu, "Oral adsorbents for preventing or delaying the progression of chronic kidney disease," The Cochrane Database of Systematic Reviews, vol. 10, Article ID CD007861, 2014.

[164] K. Eller, A. Kirsch, A. M. Wolf et al., "Potential role of regulatory $\mathrm{T}$ cells in reversing obesity-linked insulin resistance and diabetic nephropathy," Diabetes, vol. 60, no. 11, pp. 29542962, 2011.

[165] D. Zheng, Y. Wang, Q. Cao et al., “Transfused macrophages ameliorate pancreatic and renal injury in murine diabetes mellitus," Nephron-Experimental Nephrology, vol. 118, no. 4, pp. e87-e99, 2011.

[166] D. Patschan, K. Schwarze, E. Henze, J. U. Becker, S. Patschan, and G. A. Muller, "eEOC-mediated modulation of endothelial autophagy, senescence, and EnMT in murine diabetic nephropathy," The American Journal of Physiology - Renal Physiology, vol. 307, no. 6, pp. F686-F694, 2014.

[167] L. Vogt, C. Chiurchiu, H. Chadha-Boreham et al., "Effect of the urotensin receptor antagonist palosuran in hypertensive patients with type 2 diabetic nephropathy," Hypertension, vol. 55, no. 5, pp. 1206-1209, 2010.

[168] S. Yung, M. K. M. Chau, Q. Zhang, C. Z. Zhang, and T. M. Chan, "Sulodexide decreases albuminuria and regulates matrix protein accumulation in C57BL/6 mice with streptozotocininduced type I diabetic nephropathy," PLoS ONE, vol. 8, no. 1, Article ID e54501, 2013.

[169] E. J. Lewis, J. B. Lewis, T. Greene et al., "Sulodexide for kidney protection in type 2 diabetes patients with microalbuminuria: a randomized controlled trial," American Journal of Kidney Diseases, vol. 58, no. 5, pp. 729-736, 2011.

[170] D. K. Packham, R. Wolfe, A. T. Reutens et al., "Sulodexide fails to demonstrate renoprotection in overt type 2 diabetic nephropathy," Journal of the American Society of Nephrology, vol. 23, no. 1, pp. 123-130, 2012. 


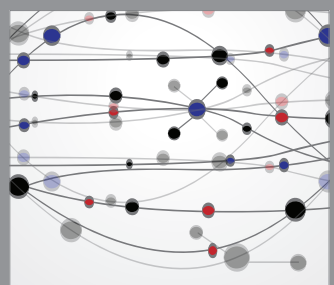

The Scientific World Journal
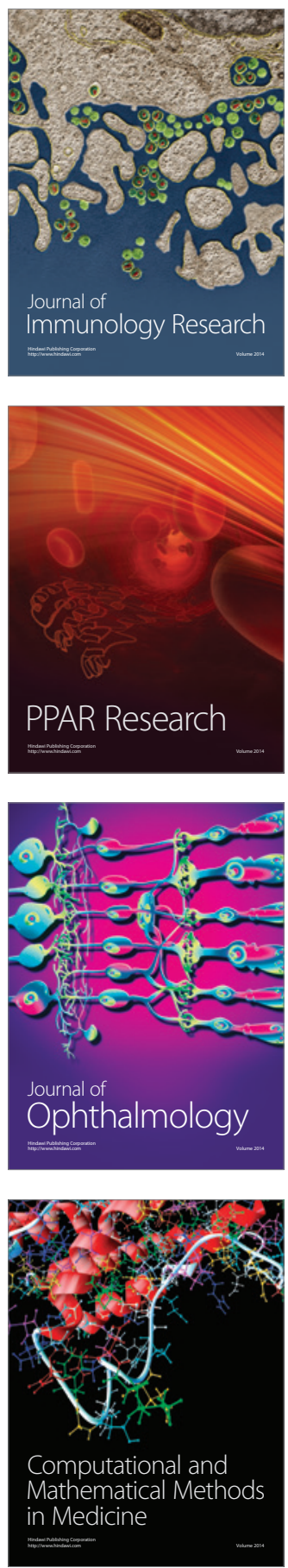

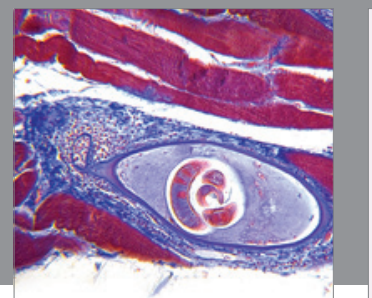

Gastroenterology

Research and Practice
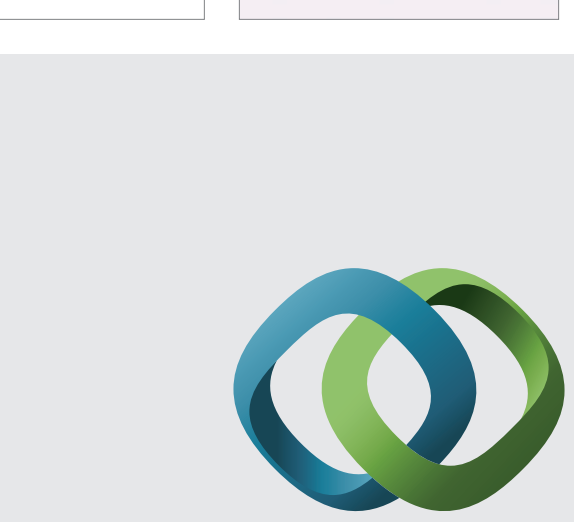

\section{Hindawi}

Submit your manuscripts at

http://www.hindawi.com
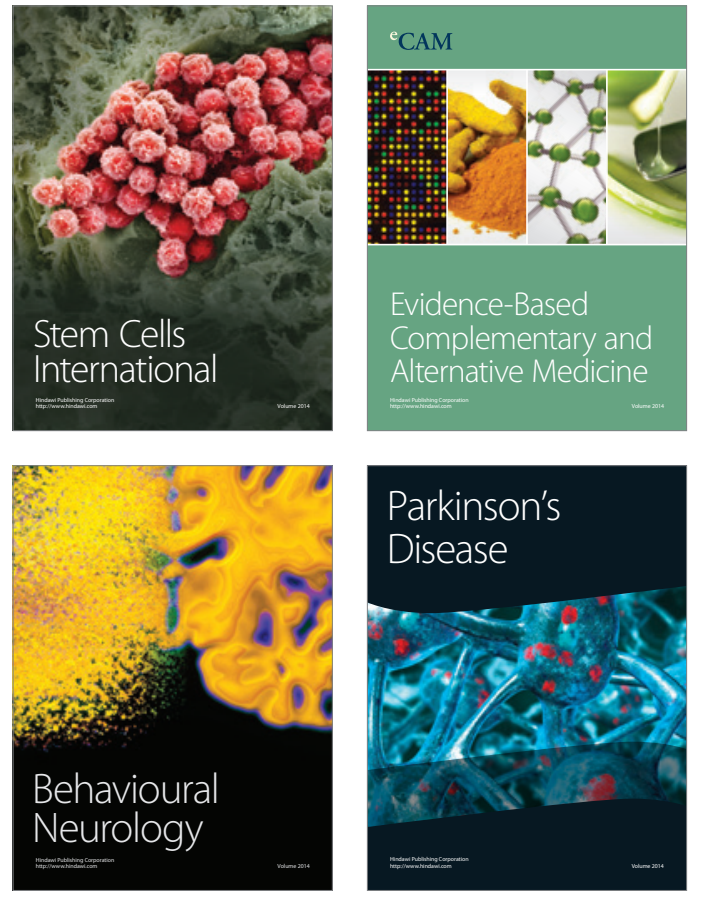
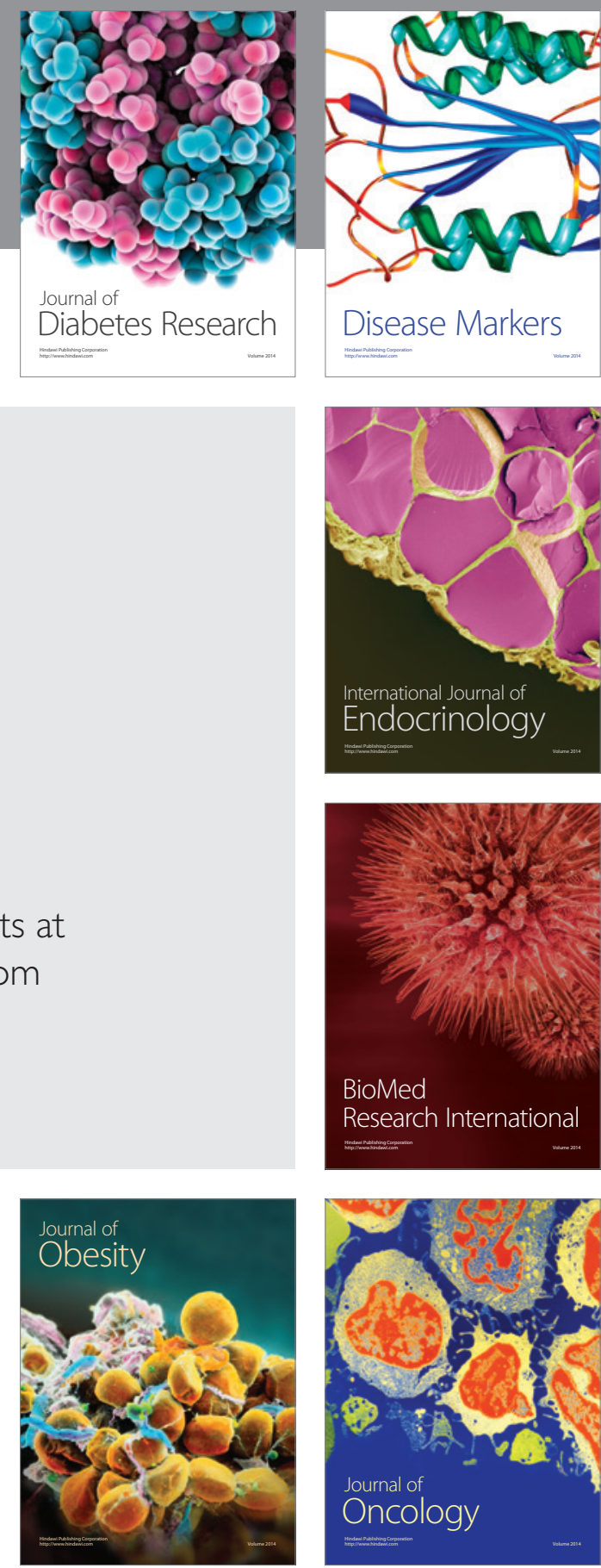

Disease Markers
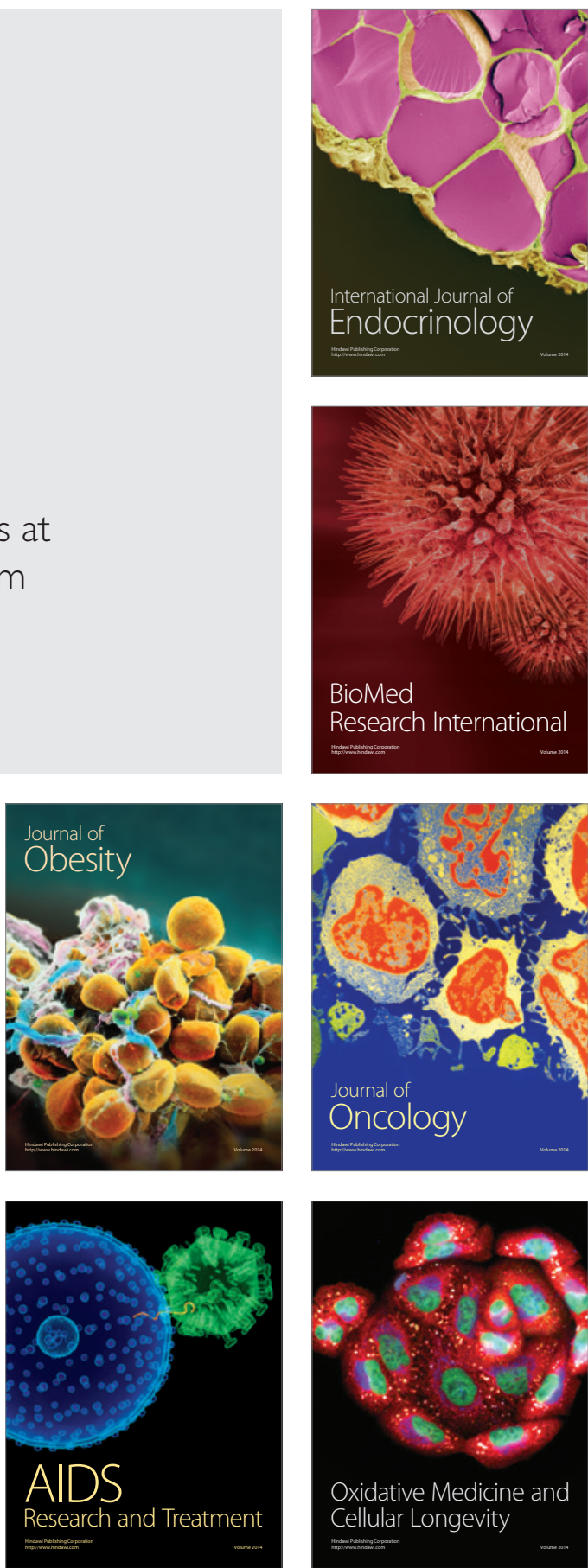